theme 1

theory

author(s) strand 3

aesthetics beyond style

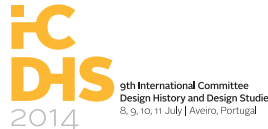

Blucher Design Proceedings Dezembro de 2014, Número 5, Volume 1

Raquel Balsa raquelbalsa@gmail.com

PhD Student in University of Aveiro

Francisco Providência correio@fprovidencia.com

University of Aveiro

Fátima Pombo fatima.teixeirapombo@asro.kuleuven.be

University of Leuven

\title{
Machine Art Exhibition, MoMA 1934 Artifacts of use displayed in the museum
}

The Machine Art exhibition determines the moment when machine and daily use artefacts took their place in an art museum. Although the Machine Art exhibition represents the foresight of MoMA's founding director Alfred H. Barr, expanding the scope of the museum beyond painting and sculpture, it was also a moment of optimistic belief in machines. Influenced by Futurism, it was a time of feverish enthusiasm fuelled by the propaganda that would enable consumerism.

It's also the moment, unlike architecture, when curators under the ideal of modernity initiate the task of establishing criteria for a museology of artifacts of design.

With this article we intended to interpret the significance of this exhibition as critical contribution to the museology of design in its relation to society; in other words, to assess the role of museum as a laboratory to shape behaviors and mentalities.

This assumes even more importance given that this article is part of a doctoral research of the first author of this study, devoted to define validation principles that can contribute to the museological treatment and the creation of an artifacts selection system for the Museum of Portuguese design.

graphic design, gated communities, identity, fairy tales, visual language

\section{Introduction}

This text aims to focus on the Machine Art exhibition as a case study about the solutions found within a particular context regarding design artifacts. How far this study will contribute to a selection system for the Museum of Portuguese Design is still soon to acknowledge considering the very beginning stage of the doctoral research. However, the approach to this event is fundamental within a historical context about the museology of design. Originated in secondary sources, the interpretation of the MOMA exhibition displayed in this text intends to depict a statement regarding the role of design museology: the object of design shown in the museum carries a kind of revolutionary potential economically, socially and aesthetically. The performance of the object of design underpins a catalyst and futuristic potential that allows to achieving the better, the further, the faster. The artifacts of design, displayed in accessible podiums in a museum became agents of transformation of the character of everyday use of objects.

With the Machine Art exhibition, Barr "saw one of his primary goals for the museum fulfilled: the incorporation of everyday objects of industrial design into the institution's exhibition program." (Marshall 2008: 597). Targeting industrial objects of everyday use, this exhibition operated two radical changes in the relationship between the museum's audience and the exhibited works, and between the beauty of the artistic work and the 
beauty of the mechanical work.

Approximately one hundred works from that exhibition were acquired, leading to the establishment of the design collection of The Museum of Modern Art (MoMA). The artifacts were displayed on pedestals "as if they were Brancusi sculptures" (Antonelli, 2013). Manifestation of formal beauty, artifacts were treated as works of art and simultaneously as items listed in a catalogue, indicating the manufacturer, the designer and the place of sale.

This paradigm shift resulted in a new social role for the museum. More instrumentalized by economy and subsequently closer to the answers to daily life practical needs. Forerunner of other demonstrations of design validation, Machine Art emphasized the functionalist dimension of material culture, sponsoring the notion of easy access for any social stratum, by contrast with the exclusivism of traditional art. It is most relevant how the museum defined the interaction between the audience and the objects shown, targeting a direct and free relationship between them through methods of display. The museum highlights the merchandise status of made in USA (machines and machine parts, scientific instruments, and everyday objects), promoting the fruition of beauty in everyday objects.

\section{Machine Art Exhibition. MoMA 1934}

The MoMA's Machine Art exhibition took place in 1934, in-between two world wars, after the Bauhaus school was closed down in Berlin, and along with a shift in American culture, in which the machine performed a key role as image, process and symbol.

This exhibition was significant to the establishment of MoMA's design collection, with the acquisition of about 100 pieces, creating the Department of Architecture and Industrial Art, so named in 1935. Between 1932 and 1934, the existing Department of Architecture was the first of its kind in an art museum. The creation of an independent curatorial department devoted to Architecture and Design was a natural development of the idea of Alfred $\mathrm{H}$. Barr, the founding director of MoMA and responsible for the initial project and purposes. A 'revelation', according to Bierut (2004), Machine Art was MoMA's first exhibition of industrially-made products, and "the fact that machines were exhibited in the same museum as paintings and sculptures was revolutionary" (MoMA, 2008). As Philip Johnson wrote in the catalog for the 1934 Machine Art exhibition:

"the twentieth century restores the art of making machines and useful objects to its place, as a technic of making rapidly, simply and well the useful objects of current life." (Riley 1994: 152).

However, industrial design objects were displayed according to the dominant model for the showing of art, the white cube. To this effect, the rhetoric of the museographic conception contributed to the new reflective and contemplative status of familiar objects. Functional domesticity experienced a new visibility due to the consecration of artifacts in the spirit of the Good Design program. Yet, paradoxically, their way of display distanced the designed objects from their primary role.

The excellence of the shape emerging from daily life, "The undeniable beauty of these objects" is presented at the exhibit, (the "museum's landmark Machine Art show"), pointing out that the "commitment to finding the sublime in the everyday has a long history." (Bierut 2004).

The celebration of functionalist aesthetics is not detached from its tangibility. The artifacts displayed have weight, shape, texture and substance. They are presented in their material and visible entirety, from all perspectives. 


\subsection{Description}

Figure 1 displays the outboard propeller which states the intention to sum up the spirit and shape of the exhibition; the admirable, attractive and dynamic performance of function:

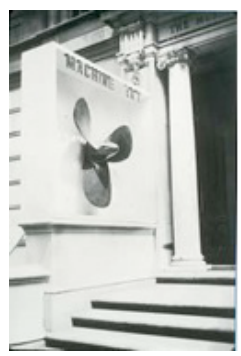

Figure 2.

MoMA's main entrance during the Machine Art exhibition (1934).

"Walls are moving, ceilings dropping, lights changing as a day-and-night shift of workmen transforms the Museum of Modern Art ...The background against which the objects will be displayed is not general but specific and has been designed to concentrate maximum attention on each object individually, yet to give a certain coherence to a display of more than a thousand items." (MoMA 1934a).

This is how MoMA presents the Machine Art exhibition in the press release from March 1, 1934. A frenzy of change dedicated to the objects available to the viewer's gaze.

"[The] Director of the Museum Alfred H. Barr, Jr., (...) valued the aesthetic merit of certain industrially manufactured objects, those created without artistic intention. ( ...) Johnson, like Barr, believed that industrial objects of good design merited aesthetic praise and validation, a conviction stemming from the Bauhaus." (MoMA 1991).

In this aesthetic sanctuary of Machine Art beauty, the implicit beauty of form converging to function, the artifacts were organized into six categories according to use:

"1. Industrial units: Machines and machine parts: springs, insulators, cable sections, propeller blades, etc.

2. Household and office equipment: Sink, furnace, bathroom cabinets, dishwasher, carpet sweeper and business machines.*

3. Kitchenware.

4. House furnishings and accessories: tableware, vases and bowls, smoking accessories, lighting fixtures, and furniture.

5. Scientific instruments: Precision, optical, drafting and surveying instruments. 6. Laboratory, glass and porcelain: Beakers, hydrometer jars, petri dishes and boiling flasks." (MoMA1934b).

The artifacts are surrounded by walls in pastel shades of pink, blue and gray, associating Functionalism to the European Neoclassicism under low ceilings with dramatically contrasting lighting. Arranged in glass shelving and expanded metal grating (an innovation at that time), objects are displayed according to three exhibit methods: variation, grouping and isolation. For the Machine Art exhibit, all spaces were filled. Walls were display stands, allowing free circulation around the artefacts along three floors. Propellers, springs, gears, cables, carpets, ball bearings, tableware, sinks and kitchen cabinets, pots, spoons and laboratory instruments integrated the 1934 MoMA exhibition.

Figure 2 displays the catalog cover designed by the newcomer in America Josef Albers, 
theme 1

theory

Figure 2. Catalog cover image for Machine Art exhibition (eBay, 1934). strand 3

aesthetics beyond style

almost completely filled by a self-aligning ball bearing manufactured by SFK Industries and designed by Sven Wingquist. Made of steel, "a ball bearing is used to connect two machine parts so that there is a minimal amount of friction when they slide against one another." (MoMA 2008). The description of each artifact includes the item's designation, designer, manufacturer, respective points of sale and price. An endnote remarked that the objects could be purchased from the manufacturer.

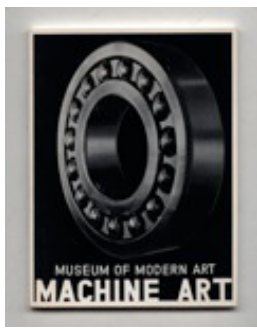

\subsection{Exhibition criteria and relationship with the audience}

The 1934 Machine Art exhibition criteria, materialized by white walls and minimalist volumes, are part of Johnson's stratagem, intended to "make people understand the importance of design" (Antonelli 2013) placing propeller blades far apart, on white pedestals, aware of their own formal beauty. Conscious of the importance of (design) forms, the resources Johnson employed did not focus singly on the beauty of design forms, but apparently also on the new program of functional valorization resulting from use.

The integration of designed artifacts as museum pieces transforms the audience perception and behavior codes. At a time when machines were praised as the agent of comfort, economic dynamism and future, their purchase is encouraged by the indication of each piece manufacturer and place of sale, thus extending the museological experience outside the museum. The nonlinear arrangement of artifacts within the exhibition means the visitor is left to wander and enjoy freely, and also represents a personal experience of liberalism, based on the exhibition of free competition of forms and brands. Along the walls of the exhibition in legible black letters are the names of American brands: Aluminum Company of America, U.S. Steel Corporation, Bingham Stamping and Tool, America Sheet and Tin Plate Company, American Radiator Company, praising industry efforts in tackling the economic crisis of the time.

\subsection{An exhibition of everyday life}

The acknowledgment of everyday life, taking it to a museum, highlights the telluric in the ordinary, in accordance to use, rules, order, looking for the "ways of operating [that] constitute the innumerable practices by means of which users re-appropriate the space organized by techniques of sociocultural production" (De Certeau 1998: 41), seeking for the reason why a whole society is not reduced to 'institutional stage directions'. And finding it in the awareness of diversity; searching for a way (of making); finding it in the 'miniscule' procedures, on details, 'beyond the stage'.

Artefacts are imported from the sphere of the ordinary, where they have already established a close relationship with the individual, onto the museum where they are available for observation upon pedestals, in a family reunion, reaching a new symbolic dimension. The Machine Art exhibition highlights objects not before considered in the museum, bringing meaning to the ordinary, thereby connoting it as exceptional. The representation of everyday life is a representation of the ordinary, the sociably shared or subjectively universal. By including manifestations of everyday life, Machine Art addressed a wide range 
of people, assuming the presented articles are familiar to them. This condition generates enthusiasm, amplified by the optimistic apology of machines; a redeeming belief considering the socio-economic situation of the U.S., undergoing the Great Depression. This exhibition overturned the authoritarian order of the Commissioner, including the public's participation in the election process to choose the most beautiful artifact.

"FOR RELEASE Monday, April 23, 1934. The public has disagreed with the judges in the vote for the most beautiful object in the Exhibition of Machine Art (...) for the aluminum outboard propeller second in the judges' list was eighth in the estimation of the public, and the third choice of the judges - the self-aligning ball-bearing - placed fourth in the popular vote." (MoMA 1934C).

Side by side with the elite appraisers ranking the artifacts in the exhibition, the acknowledgement of the public's action underlines the importance of the public in taste-shaping. In this regard, Machine Art declared to reach for more than looking at pots and propellers. Barr and Johnson suggested a model of artistic beauty, assured by timeless ideals, which according to MoMA would offer new paths for the democratization of beauty.

\section{Considerations}

The interpretation of this case study even if belonging to a research in progress allows us to stress already some considerations regarding museology, design and the debate about exhibition criteria's intentions and ideological framework.

Machine Art is an inaugural moment for the museology of design with the assignment of an aesthetic dimension to the function of the objects. In the limit the function assumes the objects' aesthetic dimension. By the exhibiting codes assumed in this event it is

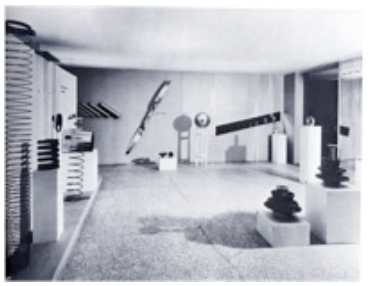

Figure 3 .

Machine Art exhibition interior (1934).

proposed that the work of industrial design is a kind of work of art democratized and produced by industry. The object is exhibited in order that its performance is admired, as art was usually admired in museums. The Machine Art transfers to the industrial object the aura attributed by the history to the work of art. Thus, the efficiency of the use replaces the uselessness of the art. The decisions and adopted solutions in Machine Art exhibition acquire even more importance by the fact that they were elaborated more through the artifacts and their meaning, their ideology about daily life and on the social moment, and less through models previously established for design exhibition.

After Machine Art experience, museums became identified with economic instruments of mediation between manufacturers and audiences, publicizing brands and consumer products. Subsequently, museums contributed directly to economic growth, with no bad conscience. It is thus suitable to argue that museums acquired a new utility beyond the traditional role of shaping aesthetic taste. Museums henceforth played a significant role in turning men into consumers and helped give birth to the liberal economic model. Demonstration of faith in the machine, in functionality, and in U. S. industry, Machine Art 'contemplative' strategy grew into a 'stratagem' to boost the use and consume of 
manufactured products.

If art is a machine to change the mind, also machines are art for social change. Borrowing the art object's aura, the artefacts designed and manufactured by the industry reach the highest level of expression of human spirituality. Accordingly, the consumerist desire is acquitted and beauty is integrated in everyday life. From the Machine Art case study became clear that the exhibition of artifacts of design was simultaneously the exhibition of a vision of the world. In a further stage of the current research will be discussed at which extent the particularities of this reported exhibition as a first encounter of museum and artifacts of design contribute to define criteria for creating a museum of Portuguese design.

\section{Acknowledgements}

This work is funded by FEDER through the Operational Competitiveness Programme - COMPETE - and by national funds through the Foundation for Science and Technology - FCT - in the scope of project PTDC/CPC-DES/4754/2012 (FCOMP-01-0124-FEDER-028530).

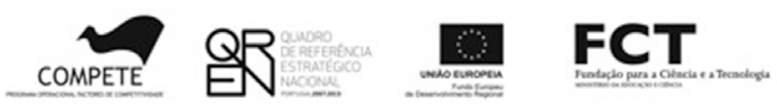

\section{Bibliography}

_Antonelli, P. (2013) Why I brought Pac-Man to MoMA. New York. http://www.ted.com/ talks/paola_antonelli_why_i_brought_pacman_to_moma.html [Accessed: 1st June 2013]. _Bierut, M. (2004) To Hell with the Simple Paper Clip. http://observatory.designobserver. com/entry.html?entry=2377 [Accessed: 1st November 2013].

_De Certeau, M. (1998) A invenção do cotidiano: artes de fazer. Petrópolis, Vozes. _eBay. (2013) http://www.ebay.com/itm/1994-Philip-Johnson-MACHINE-ART-MoMA1934-Streamline-Industrial-Design-Catalog-/310777496636 [Accessed: 1st November 2013]. _The grapes of wrath. (1940) [DVD] USA, Twentieth Century Fox Film Corporation. _Lowry, G. (2003) Foreword. In: Antonelli, P. \& Bee, H. (eds.) Objects of design from the museum of modern art. New York, The Museum of Modern Art, p. 6.

_Marshall, J. (2008) "In Form We Trust: Neoplatonism, the Gold Standard, and the Machine Art Show", 1934, The Art Bulletin, pp.597-615.

_MoMA. (1934a) http://www.moma.org/pdfs/docs/press_archives/162/releases/ MOMA_1933-34_0029_1934-03-01.pdf?2010 [Accessed: 1st November 2013]. _MoMA. (1934b) http://www.moma.org/pdfs/docs/press_archives/164/releases/ MOMA_1933-34_0031_1934-03-03.pdf?2010 [Accessed: 1st November 2013]. _MoMA. (1934C) http://www.moma.org/pdfs/docs/press_archives/173/releases/ MOMA_1933-34_0040_1934-04-23.pdf?2010 [Accessed 1st November 2013]. _MoMA. (1991) MoMAhttp://www.moma.org/learn/resources/archives/archives_ highlights_10_1991 [Accessed: 8th June 2013].

_MoMA. (2008)

http://www.moma.org/pdfs/moma_learning/docs/design_full.pdf [Accessed: 8th December 2013].

_Pricola, J. (2003) Art for Trade's Sake. The Fusion of American Commerce and Culture 1927-1934. http://xroads.virginia.edu/ mao3/pricola/art/machine.html [Accessed: 1st November 2013].

_Riley, T., \& Eigen, E. (1994) Between the Museum and the Marketplace: Selling Good Design. In: Elderfield, J. (ed.) Studies in Modern Art 4. The Museum of Modern Art at MidCentury: At Home and Abroad. New York, Museum of Modern Art, pp. 150-179. 